\title{
Why are European IPOs so rarely priced outside the indicative price range?*
}

\author{
Forthcoming, Journal of Financial Economics
}

\author{
Tim Jenkinson \\ Alan D. Morrison \\ William J. Wilhelm, Jr. \\ Saïd Business School, Saïd Business School, \\ McIntire School of Commerce, \\ University of Oxford; University of Oxford; \\ University of Virginia; \\ CEPR. \\ CEPR. \\ Saïd Business School, \\ University of Oxford; CEPR.
}

This version: May, 2005

\footnotetext{
${ }^{*}$ We thank Bill Schnoor and Howard Jones for sharing their legal and institutional expertise and Rajesh Aggarwal, David Goldreich, Giancarlo Giudici, Alexander Ljungqvist and Ann Sherman for providing valuable feedback. We are grateful to the referee for extremely detailed and insightful comments which materially improved the paper. We also thank Alexander Ljungqvist for organizing the data reported in table I.

Correspondence address: Tim Jenkinson, Saïd Business School, Park End Street, Oxford OX1 1HP, UK. email: tim.jenkinson@sbs.ox.ac.uk. Alan Morrison, Merton College, Oxford, OX1 4JD, UK. email: alan.morrison@sbs.ox.ac.uk. William J. Wilhelm Jr., McIntire School of Commerce, Monroe Hall, Charlottesville, VA 22903
} 


\title{
Why are European IPOs so rarely priced outside the indicative price range?
}

\begin{abstract}
Unlike the US, the initial price range for European IPOs is seldom revised, although issues are often priced at its upper bound. We develop a model which explains this seemingly inefficient pricing behavior. As in Europe, but not in the US, underwriters in the model obtain information from investors before establishing the indicative price range. A commitment to stay within the range is necessary to extract private information from investors. Ours is therefore the first treatment in which the bookbuilding range has a clear economic role. The model has important implications for empirical research based on European primary market data.

KEY WORDS: IPO underpricing; bookbuilding; information acquisition.

JEL Classification: G24; G32
\end{abstract}

\section{Introduction}

In the last decade, the use of bookbuilding as a means of conducting securities offerings has spread from the United States to most other major countries. In the case of equity initial public offerings (IPOs), bookbuilding is now used in over four-fifths of all non-US offerings (Ljungqvist, Jenkinson and Wilhelm, 2003). Whilst in many respects bookbuilding procedures for IPOs are similar across countries, there are some important differences. This paper focuses on one particular distinction between US and European practice regarding IPOs: how the ability of investment banks in European IPOs to elicit information from investors prior to setting an initial indicative price range changes the nature of the information revelation problem facing the investment banking syndicate. Our theoretical model offers an explanation for a striking empirical discrepancy between US and European IPOs: the relatively infrequent pricing of European IPOs outside the initial indicative price range. Whereas in around one-half of US IPOs the final price is set outside the initial price range, only one-tenth of European IPOs are priced outside the initial range. 
In the US, communications with investors are guided by the 1933 Securities Act. The Act requires that investors receive financial and other significant information concerning securities being offered for public sale and prohibits deceit, misrepresentations, and other fraud in the sale of securities. Section 5 of the Act prohibits any "offer" prior to the filing of a registration statement. Banks' legal advisors interpret the US regulatory framework as discouraging contact with investors during the pre-filing period, beyond the circulation of a "pink herring", which contains little more than basic factual information and announces that the company concerned is considering an offer.

Investors in US offerings are only asked to reveal their views about the IPO once the registration statement, including an initial indicative price range, has been filed. During the registration period, and for 40 days after the IPO (the "quiet period"), the company and their advisors are able to present statements of fact, but are not allowed to publish any opinions regarding the valuation of the company (see Bradley, Jordan and Ritter, 2003, and Ritter, 2003). Research analysts associated with members of the investment banking syndicate are important in providing post-IPO coverage, but do not produce their first reports until the end of the quiet period. During the bookbuilding phase - which involves road-show presentations, one-on-one meetings with selected investors, and direct marketing by members of the investment banking syndicate - bids are submitted to the bookrunner who constructs a demand curve for the issue. If demand is strong the initial price range can be revised. Within this institutional context Benveniste and Spindt (1989) first analysed how investment banks can provide investors with incentives to reveal information regarding the value of the firm.

Within Europe the exchange of information between investors and the investment banking syndicate can occur earlier, before the initial price range is set. This reflects less strict interpretation of securities laws within Europe ${ }^{1}$ as there are few formal regulations that prescribe the details of how an offer should be conducted. The research analysts associated with the investment banking syndicate routinely produce written research reports prior to the offering's registration. Draft reports are typically vetted by the lead manager(s) to ensure "consistency" before being distributed by syndicate members to potential investors. Usually, the research reports give an indication of the valuation range that the analyst believes is reasonable. Key investors are offered meetings with the

\footnotetext{
${ }^{1}$ Although regulations vary from country to country, bankers for European offerings apparently defer to what they perceive as the more demanding constraints imposed by authorities in London. In any event, the pre-marketing practices we describe occur throughout Europe and for the purpose at hand it is unneccessary to draw fine distinctions between individual European markets.
} 
syndicate's analysts to discuss the offering. Subsequently, they are asked for feedback regarding the price at which they would subscribe. The formality of the process varies considerably across IPOs. At its most formal, investment banks request responses to extensive questionnaires that survey the investor's investment strategy and holdings as well as its reaction to the company and its thoughts on valuation. The information gathered during this pre-marketing phase can then be taken into account in setting the initial indicative price range. Conditional upon the price range, the investors can then submit formal bids.

Although these differences in practice are driven by alternative interpretations of securities law in the US and Europe, they nonetheless constrain the conduct of IPOs. As we explain in the next section, interactions with potential investors prior to registration that are routine in Europe are stictly prohibited in the US. Furthermore, one of the complexities associated with targeting investors in both the US and Europe is the need to observe the different sets of rules. We know of one case where a syndicate member inadvertently distributed research intended for European investors by email to US investors during the pre-marketing phase and was promptly thrown out of the IPO syndicate.

The ability of the investment bank to canvass the opinion of investors in Europe prior to setting the initial price range adds complexity to the information revelation problem facing the syndicate. In this paper we present a model based upon these European conventions, in which the investment bank asks particular ("informed") investors for their views on the value of the IPO prior to setting the initial price range. Knowing that positive feedback drives up the offer price, investors have an incentive to understate their beliefs. But this incentive distortion can be resolved by simultaneously committing to not exceed the indicative price range regardless of feedback during the bookbuilding effort and to favor all other ("uninformed") investors in the event of oversubscription. The result depends on a positive probability that private information will be exogenously revealed to uninformed investors prior to the offering being completed. With this threat, and a firm commitment to the upper bound of the indicative price range, informed investors run the risk of being crowded out at the offering if they understate their beliefs in communications on which the investment bank conditions the indicative price range. We show that, in equilibrium, this mechanism induces information production and truthful revelation.

Previous models of the bookbuilding process (see for example Sherman and Titman, 2002, and Sherman, 2003) have emphasised the importance of the order book as a way of restricting 
participation in the share offering so as more efficiently to incentivise information production. Pecuniary incentives for participation in these models are provided by under-pricing the new issue and there is no specific role for the price range. In contrast, our model provides a first explanation for the use of a range, whose level and width both serve to reveal information and to provide incentives. Moreover, in the European setting which we examine, participation can be restricted at the premarketing phase and so need not be restricted at the bookbuilding phase. In fact, unrestricted participation in the bookbuilding is desirable in our model to provide adequate incentives to the informed agents.

Although we do not provide a formal test of our model, we show how this alternative staging of the information game may help to explain one of the main discrepancies observed between US and European IPOs. In the US, the final price is frequently set outside the initial price range, whereas in Europe the final price is usually within the initial price range, and very frequently at the boundaries of the price range (we present evidence on this in the next section). In our model this stickiness of the initial price range is not inefficient or the result of institutional rules. It is an essential component of the mechanism for inducing information revelation. Furthermore, our model may help to explain the lack of price-limited bids ("limit bids") observed by Jenkinson and Jones (2004) in their analysis of European IPOs. In our model, informed investors do not reveal information via limit bids during the bookbuilding phase, but rather reveal their information earlier and then submit strike bids.

The remainder of the paper proceeds as follows. In the next section we discuss the institutional setting in more detail and present evidence on the conduct of IPOs in Europe. In section 3 we present the theoretical model. In section 4 we discuss the role of the two-stage information gathering process and the price range in our model, and we discuss some extensions to our basic set-up. Conclusions and a discussion of the implications of the alternative staging of the information game for empirical analyses of European data are contained in section 5.

\section{The Institutional Setting}

In many respects the spread of bookbuilding to countries outside the US has resulted in greater similarity of IPO procedures. This is particularly true of the bookbuilding period itself, during which the investment banking syndicate markets the issue to potential investors, and orders are 
entered into the industry-standard bookbuilding software. However, in this section we argue that there are a number of important "micro-structure" differences in the conduct of IPOs. We start by examining in detail the nature, extent, and timing, of information exchange between investors and the syndicate. We then consider any constraints due either to regulation, or to custom and practice, that affect the setting and revision of price ranges. Finally, in this section, we briefly discuss the stylised facts regarding the accuracy of initial price ranges and final issue prices.

\subsection{Information exchange}

In figure 1 we compare the various stages of an IPO in the US and in Europe. In the US the 1933 Act splits the offering process into three distinct periods. Securities cannot be offered to the public unless a registration statement has been filed. In the pre-filing period the issuing company (and its advisors) are not allowed to say anything that could constitute an offer to sell. This includes any publicity or material that has the effect of "conditioning the public mind or arousing public interest in the issuer or in the securities of an issuer". Clearly, this would include research produced by analysts. If the SEC judges that any relevant information has been released, the company can be subject to "gun-jumping" rules that require a cooling-off period before any offering is permitted. Although no precise rules define when a company enters a pre-filing period, lawyers generally advise that once the lead underwriter has been appointed the company is essentially considering an issue, and so becomes subject to these restrictions on releasing information. In practice, therefore, the pre-filing period can extend for some months before any filings are made with the SEC.

The second stage of the IPO process in the US is the waiting period, which starts when the registration statement is filed with the SEC. The first part of the registration statement is a provisional prospectus, or "red-herring". Provided it complies with section 10b of the Act the red herring can be distributed to potential investors. ${ }^{2}$ One key element of incompleteness is that the red herring will normally include an indicative range for the issue price. ${ }^{3}$ It is important to note that in the US all relevant (and sometimes, irrelevant ${ }^{4}$ ) information regarding the offering must

\footnotetext{
${ }^{2}$ The provisional prospectus must include the following statement: "The information in this prospectus is not complete and may be changed. We may not sell these securities until the registration statement filed with the Securities and Exchange Commission is effective. This prospectus is not an offer to sell these securities and we are not soliciting any offer to buy these securities in any jurisdiction where the offer or sale is not permitted." The term red herring derives from the fact that until recently, this statement had to be in red ink.

${ }^{3}$ Rule $430 \mathrm{~A}$ permits a registration statment becoming effective without an indicative price range, which can then be included in the final prospectus.

${ }^{4}$ For instance an interview with the two founders of Google, which was conducted before the announcement of
} 


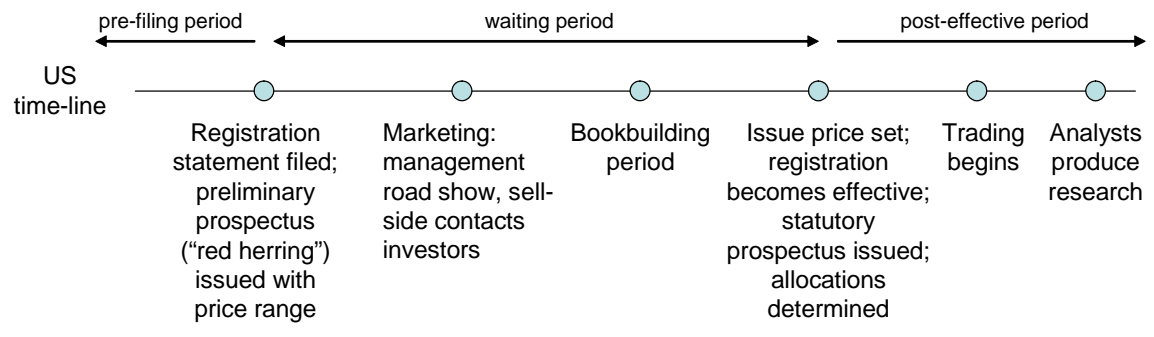

\begin{tabular}{|c|c|c|c|c|c|c|c|}
\hline & $\begin{array}{l}\text { Analysts } \\
\text { produce } \\
\text { research }\end{array}$ & $\begin{array}{l}\text { Pre-marketing: } \\
\text { sell-side } \\
\text { contacts } \\
\text { investors }\end{array}$ & $\begin{array}{l}\text { Preliminary } \\
\text { ("pathfinder") } \\
\text { prospectus } \\
\text { issued with } \\
\text { price range }\end{array}$ & $\begin{array}{l}\text { Marketing: } \\
\text { management } \\
\text { road show }\end{array}$ & Book-building & $\begin{array}{l}\text { Issue price } \\
\text { set; final } \\
\text { prospectus } \\
\text { issued; } \\
\text { allocations } \\
\text { determined }\end{array}$ & $\begin{array}{l}\text { Trading } \\
\text { begins }\end{array}$ \\
\hline
\end{tabular}

Figure 1: Timelines for US and European IPOs

be contained in the prospectus. Analyst research still cannot be issued by the selling syndicate. During the marketing and bookbuilding periods that follow, investors evaluate the issue and may share information with the banks advising the issuer. Based on the formal bids, and the informal feedback, the final issue price is either set within the indicative range; or a new range is filed with the SEC, and the price is set within the revised range.

Once the registration statement has become effective, and the statutory prospectus - which must satisfy section 10a - has been approved and issued to potential investors, the offering enters the post-effective period. Allocations are finalised and trading begins soon afterwards. After 40 days, the quiet period ends and research analysts are able to start distributing their views on the company.

In Europe, the interpretation of securities laws by regulators and legal counsel results in a very different sequence of events. In general the result is that information is produced, distributed and exchanged much earlier in the IPO process. As figure 1 shows, after the lead underwriter(s) have been appointed, the next stage is for analysts to produce research notes. In smaller IPOs the bulk of such research is conducted by analysts associated with the underwriting syndicate, but in

their recent IPO, appeared in Playboy magazine during the period when bids were being invited for the offering. As a result, the prospectus was amended to include the entire interview (see Appendix B of the S1 registration document), and a new risk factor added: "If our involvement in a September 2004 magazine article about Google were held to be in violation of the Securities Act of 1933, we could be required to repurchase securities sold in this offering. You should rely only on statements made in this prospectus in determining whether to purchase our shares." Fascinating though the article undoubtedly is, it is difficult to spot any incremental information of relevance to investors. 
the larger IPOs research may be produced by those uninvolved with the IPO. ${ }^{5}$ This research is distributed by syndicate members to institutional clients who are then contacted for their views on the issue before the price range is set or any formal documentation is filed. We refer to this phase as the pre-marketing period. We illustrate the nature of this interaction between investors and the sell-side with an example of a recent large European privatisation.

This IPO involved about forty investment banks, and four separate placement syndicates were formed. These syndicates had exclusive selling rights for their respective geographical areas, which were (1) the country of origin of the issuer (2) the US (3) Japan and (4) the rest of the world. Separate placement syndicates were created for Japan and the US explicitly because the distribution of research during the pre-marketing period is prohibited in these countries. In Europe and the rest of Asia (excluding Japan) no such prohibition exists. Hence, Canada, which does allow the distribution of pre-IPO research, was included in the rest of the world syndicate rather than alongside the US. Research reports, including forecasts of future earnings, were then distributed to institutional investors in the home country and rest of the world syndicates. These investors were then asked to fill out a detailed feedback form which asked for information about the investor (e.g. whether they were index-trackers, asset allocators, or stock pickers), their total assets under management and current weighting in the sector and country, their perceptions of the firm going public, whether they would attend the road-show or wanted a one-on-one meeting, their views on the appropriate share price and what they considered the key valuation ratios, and finally whether they were likely to invest and, if so, how much.

The formality, and the extent, of the information gathering during the pre-marketing varies somewhat across European IPOs. In many cases investors are not asked explicitly for their views on the appropriate price per se, but are polled on factors from which a view on the price range can be inferred - such as key valuation drivers, the most appropriate comparators etc. Often such information is gathered by the sales force in meetings with investors. In large offerings, and where there is active competition among the selling syndicate for commission, feedback may be gathered from a few hundred investors. In smaller offerings, the pre-marketing is usually less intensive. ${ }^{6}$

\footnotetext{
${ }^{5}$ The 2001 IPO of the mobile phone company Orange (which was floated by its parent France Telecom) shows the extent of the information that can be disseminated in the pre-marketing period. The Financial Times (20 Dec, 2000) reported that 160 analysts, a large proportion of whom were independent of the underwriting syndicate, attended a 9 hour "briefing" one month before the start of the roadshow.

${ }^{6}$ One investment banker remarked to us that for most issues they would focus their attention on getting the feedback from the top fifty investors, whose "price talk" usually spanned the views in the market.
} 
The important distinction between European and US bookbuildings, however, is that there is considerably greater opportunity in Europe than in the US to exchange information early in the process. Hence the information revelation problem involves incentivising investors to become informed, and to reveal valuable information that can be fed into the initial price range. This is not to say that there is no contact between US investors and the underwriter in the pre-filing period, but there is simply much less information available to US investors upon which to base an opinion of the appropriate price. Indeed, in its recent global analyst research settlement, the SEC has explicitly prohibited any role for research analysts in pitching for IPO business, or participating in roadshows or any other selling activity. ${ }^{7}$

After opinions on the issue have been solicited, a preliminary "pathfinder" prospectus is issued to potential investors. The subsequent marketing and bookbuilding stages are very similar to the US, except that since investors have previously been contacted during the pre-marketing period in Europe there is less need for interaction with the sell-side. At the end of the bookbuilding the price is set, and the definitive prospectus is issued.

There are, of course, some regulatory differences between European countries. ${ }^{8}$ But in general European investment banks can, and do, engage in substantive discussions with investors before the price range is set. Given this early information exchange, the indicative price range would be expected to be more accurate in Europe than in the US. However, regulatory constraints make such simple comparisons difficult.

\subsection{Setting and revising the initial price range}

As detailed in section 3 , the initial price range has an important function in our model as a commitment device. However, there are certain practical constraints on how the price range is set and revised. Some constraints are imposed by explicit regulation, usually concerning the content and revision of prospectuses, but more often they relate to the interpretation of general principles. Furthermore, in some countries IPOs can involve hybrids of bookbuilding and fixed price offers, which can also have implications for the conduct of the offering. We consider these issues in turn.

\footnotetext{
${ }^{7}$ See www.sec.gov/news/speech/factsheet.htm.

${ }^{8}$ For example, the German stock exchange introduced a code of conduct for IPOs in September 2002 that prohibits syndicate banks from releasing research to investors in the two weeks prior to the offering. However, this does not impact on their ability to exchange information with investors during the pre-marketing period (or at any stage outside the two week blackout period). Furthermore, non-syndicate banks face no such restrictions, and will normally be supplied with the same detailed financial information upon which to base their research.
} 
In the US, the Securities and Exchange Commission (SEC) Regulation S-K concerns the information that must be included in the prospectus and provides general principles guiding the price range. The issuer is required to provide a "bona fide estimate of the range of the maximum offering price and the maximum number of securities offered" (see Item 501(b)(3)). This leaves open to interpretation the required precision of a bona fide estimate of the price range. Until September 2001, the SEC guidance provided a "safe harbor" for issuers who limited their price range to the greater of $\$ 2$ or $10 \%$ of the lower price. This resulted in an observed tendency to set a price range of exactly $\$ 2$ and a price range within the $\$ 10-\$ 20$ range. The convention was for less established issuers to have lower issue prices but the same $\$ 2$ range, which resulted in a wider proportionate price range. The SEC relaxed its guidance in the volatile post-September 2001 financial markets, by allowing the safe harbor to apply if the price range were limited to the greater of $\$ 2$ or $20 \%$ of the lower price. However, the SEC has discretion in interpretation, and in certain cases has clearly been prepared to authorise price ranges wider than these guidelines. ${ }^{9}$ Hence, the width of the price range in the US tends to be governed by convention, rather than related to intrinsic uncertainty.

[Table 1 here]

As a result of the above conventions, the width of the price range in US IPOs has averaged around $15 \%$. This can be seen in table 1 , which provides a summary of the pricing behavior for the eight most active European markets during the January 1994 - July 1999 period, along with equivalent evidence for the US. ${ }^{10}$ However, although the initial price range in the US is clearly constrained by regulation, the significance of the initial range is reduced by the fact that the range can be revised, and the final price set outside the initial range. As table 1 shows, in one half of all US IPOs the final offer price was set outside the initial price range, with similar proportions being set above and below. In contrast, although the average width of the initial price range across the whole European sample is similar to that observed in the US, the final price was set outside the initial price range in just over 10 percent of IPOs. ${ }^{11}$ Furthermore, the final price was set strictly at the high end of the initial range in nearly 47 percent of European IPOs, compared with 19 percent of US IPOs.

\footnotetext{
${ }^{9}$ For example, in the Google IPO in July 2004 , the width of the initial price range of $\$ 108-\$ 135$ was $25 \%$ of the lower bound.

${ }^{10}$ We are very grateful to Alexander Ljungqvist who prepared this data for us.

${ }^{11} \mathrm{It}$ is noticeable that there is no obvious clustering of price ranges in Europe, either in absolute (local currency) terms, or in percentage terms. We also investigated whether the level, or recent volatility, of local market indices influenced the width of European price ranges, but found no relationship.
} 
In most European countries, custom and practice has arguably been more important than formal regulation. ${ }^{12}$ Stock exchange rules and securities regulations in Europe tend to establish general principles rather than to specify rules regarding particular offering methods. It should be remembered that until the mid-1990s, most European IPOs were conducted as public offerings, usually at a fixed price but occasionally using auction mechanisms. Bookbuilding increasingly came to be used, but in some countries custom and practice continued to reflect previous fixed price methods. This is particularly true of Germany and Italy, where pricing outside the initial price range virtually never happened over the sample period considered in table 1 .

In the case of Germany, of the 224 German IPOs sold using bookbuilding methods none were priced above the top of the indicative price range, and 161 (72 per cent) were priced at the upper bound. In part, this may be explained by the tendency of German retail investors to participate in the bookbuilding (via their local banks). The need to contact many individual investors to reconfirm demand would certainly increase the cost of revising price ranges. However, such costs could clearly be reduced by moving retail orders online and, indeed, several German banks did this in the late 1990s. Furthermore, Löffler, Panther and Theissen (2002) suggest that German pathfinder prospectuses have only recently allowed for upward adjustment of the bookbuilding range in response to overall market or specific demand conditions. This is similar to the situation in Italy: when bookbuilding was introduced into Italy in the late 1990s, most issuers committed in the pathfinder prospectus to price their IPOs within the price range indicated. Although it would have been possible to withdraw or to amend the pathfinder prospectus and issue a new one with a different price range, this did not happen. ${ }^{13}$ Companies started removing such commitments from 2000 onwards, and stated explicitly that the price range was only indicative. Nonetheless, pricing outside the initial range remains rare.

Hence, although there may be some differences in the way bookbuilding has been executed across European countries, pricing outside the initial price range is consistently much less common than in the US. In both Europe and the US, the main costs incurred in revising the price range are the need

\footnotetext{
${ }^{12}$ For those countries that are members of the European Union important aspects of securities issues are to be governed by the Prospectus Directive and the Market Abuse Directive, both of which will apply from 1 July 2005. With regard to the information required in prospectuses, the EU regulations will simply require "An indication of the price at which securities will be offered. If the price is not known ... indicate the method for determining the offer price, including a statement as to who has set the criteria or is formally responsible for the determination." (see European Commission Regulation 809/2004, Annex III, section 5.3.1).

${ }^{13}$ In the case of German IPOs on the Neuer Markt, Aussenegg, Pichler and Stomper (2002) suggest that investment banks were concerned about possible legal action resulting from setting the offer price outside the range published in the pathfinder prospectus.
} 
to file an amendment to the registration statement (or to revise the pathfinder prospectus), and the requirement for the syndicate to check that the indiciations of interest from investors are still valid at the amended price. In general, neither of these is likely to delay the issue significantly, and the extra effort will generally be borne by the investment banking syndicate. However, changing the price range might involve somewhat more significant frictions for those IPOs that involve hybrid offerings.

In hybrid offerings, bookbuilding is used for insitutional investors and a public offering is targetted at retail investors. Hybrid offerings are quite common in Europe. In recent years, such offerings have typically occurred simultaneously, although sequential offerings - where the public offering follows the bookbuilding - used to be common. ${ }^{14}$ Whether the hybrid nature of an offering influences the ease with which the price range can be changed depends on how the public offering is structured. In a simultaneous hybrid offering, the price established from the institutional bookbuilding is often used as a reference price for the retail offering: retail investors are asked to submit orders on the basis that the final price will be either equal to, or, more commonly, at a defined discount to, the price established in the bookbuilding. This allows the bookbuilding and retail offering to take place simultaneously, and revisions to the price range in such simultaneous offerings should be straightforward, as retail investors submit quantity (rather than price-sensitive) bids. ${ }^{15}$ In the case of sequential offerings where the public offering does not start until the bookbuilding is completed, late revisions to the price range in the bookbuilding may delay the start of the public offering. However, such offerings have become extremely rare.

Therefore, although there are some differences in regulation and practice between the US and Europe, and within Europe, in general price range revisions appear no more onerous in Europe than in the US. Given these differences in the timing of information flows, and the observed stickiness of the initial price range in Europe, we next consider whether initial price ranges are more accurate outside US, and how final offer prices relate to the initial price range.

\footnotetext{
${ }^{14}$ Sequential hybrids have died out in the main because issuers often required the offering to be underwritten (at the price arrived at in the bookbuilding) for the several days that it took to complete the public offering. Unlike conventional bookbuilding, where the underwriting risk is virtually non-existent, sequential offerings therefore required the underwriters to assume significant risk.

${ }^{15} \mathrm{In}$ a few European offerings, retail investors have been asked to confirm their bids when the price range in the bookbuilding has been changed. For instance, in the IPO of mobile phone company Orange referred to earlier, retail investors (who were being offered a discount of 0.5 euro on the price arrived at via bookbuilding) were asked to confirm their bids even though the price range was revised downwards. However, the re-contacting of investors was completed in a few days and did not delay the timetable for the IPO, as the price range was revised mid-way through the bookbuilding period.
} 


\subsection{Underpricing}

Consider first the width of the initial price ranges. Ceteris paribus, one might expect ranges to be wider in the US, where less information is available when the range is established. However, such simple comparisons with Europe are invalidated by US regulations which constrain the width of the price range. In fact, table 1 shows that the average width of the price range does not differ significantly between most European countries and the US.

Next, given that price ranges are much less frequently revised outside the US, does average underpricing differ significantly? Various authors have extended the Benveniste and Spindt model in the context of the US institutional arrangements so as to explain how optimal mechanisms for extracting private information from investors require discriminatory share allocation and a partial adjustment to positive news from investors (Benveniste and Wilhelm, 1990; Hanley, 1993; Sherman and Titman, 2002). Consistent with the theory, US IPOs are commonly priced above the upper bound of the indicative price range and still exhibit large first-day returns. In contrast, Aussenegg et al. (2002), in their study of German IPOs, find no such partial adjustment phenomenon. In table 1 we measure underpricing in two ways. Firstly, we examine underpricing relative to the mid-point of the initial price range, which gives a measure of the accuracy of the initial price range. If the initial price range is very sticky in Europe then it is particularly important that it is accurate. Secondly, we report underpricing relative to the final issue price. This provides a measure of how much money is "left on the table."

For the sample as a whole, initial price ranges are, on average, seven percentage points more accurate in Europe than in the US. This is consistent with our earlier observation that initial price ranges are based on more information in Europe than in the US. It is noticeable that Germany is very much an outlier in respect of underpricing during the sample period, and may also, as discussed earlier, have been subject to slightly different practice in the initial years after bookbuilding was introduced. If Germany is excluded from the European sample, the average underpricing relative to the initial price range falls to $15.1 \%$, which is significantly lower than the $34.7 \%$ observed in the US. As expected given the greater frequency of price ranges in the US, differences in underpricing relative to the issue price are much smaller, with European IPOs experiencing around 3 percentage points less underpricing on average than US offerings.

Of course, these are simple averages and do not allow for any compositional effects in the samples 
of IPOs, nor for timing differences (given that we know that IPO returns are subject to hot issue periods), nor for the various factors that might influence the accuracy of IPO pricing (on this see Ljungqvist, Jenkinson and Wilhelm, 2003). Viewed through a US institutional lens, the infrequency of revisions to initial price ranges, and the clustering of offer prices at the top of the initial ranges, which are observed in Europe appears inefficient. However, the stylised evidence suggests that for most European countries initial price ranges are more accurate, and that less money is left on the table.

In the next section we present a model of the bookbuilding process in which investors can become informed, and reveal information to the investment banking syndicate in the pre-marketing phase. We have argued above that this assumption reflects European institutional arrangements. In our model an implict commitment from the investment banker not to set the price outside the initial price range plays an essential role in incentivising information production. Hence, we show that under European insitutional frameworks, sticky initial price ranges may serve to increase the efficiency of the IPO process.

\section{The Model}

We consider a simple model in which an investment bank wishes to sell $\$ S$ of a share whose fair price $\tilde{P}$ is $P_{h}$ or $P_{l}=P_{h}-\Delta P<P_{h}$, with respective ex ante probabilities $\pi_{h}$ and $\pi_{l}$, where $\pi_{l}+\pi_{h}=1$. There is a universe of $I+1$ potential risk neutral investors in the share.

Investor 0 is endowed with $\$(1+c)$ and an information technology which, in return for an initial investment of $\$ c$, returns a perfect signal of $\tilde{P}$. Whether or not investor 0 has used her information technology is unobservable.

Investors $1,2, \ldots, I$ are each endowed with $\$ 1$. They have no information technology but with probability $\lambda<1$ they all learn the security's value. We refer to these investors as "uninformed". We think of uninformed investors as being either individual investors or investing institutions. Uninformed investors may in addition have an exogenous need to invest: this happens when they (or their clients) have surplus funds to place, with probability $\beta$. This need may arise when they make windfall gains in a booming economy. We assume that windfall investors are fully rational, in contrast to the liquidity traders of the market microstructure literature. Hence, they will never pay more than the expected true value of the shares. We assume that learning (with probability 
$\lambda$ ) and windfall investing (with probability $\beta$ ) are independent events.

Lastly, we assume that

$$
I>S,
$$

so that equilibrium share rationing is possible.

We assume that the investment bank wishes to price the issue as accurately as possible. We do not endogenise this aspect of the model: previous authors have argued that accurate pricing may be important in order to facilitate future fund raising (Chemmanur, 1993), to avoid adverse selection problems in aftermarket trading (Busaba and Chang, 2002), to generate valuable market feedback upon the issuer's business plan (Sherman, 1992), because uninformed investors are risk averse (Sherman, 2000), or to provide implict insurance against the costs of litigation (Tinic, 1988). We simply assume that either the issuer or the investment bank places a sufficiently high value upon price accuracy to be prepared to pay for it. The investment bank's objective is then to design a mechanism to induce investor 0 to use her information technology and to reveal her information so that it can be incorporated into an indicative price $p$.

The mechanism is staged as follows:

$t_{0}$ The bank asks investor 0 to report a price $p$ for the share and to bid for the share;

$t_{1}$ The bank quotes a price range $\left[p-d_{p}, p\right]$ for the share and asks the remaining $I$ investors to bid for the share;

$t_{2}$ With probability $\lambda$, the remaining investors learn $\tilde{P}$ and with probability $\beta$ they need to invest a windfall;

$t_{3}$ Investors decide whether to bid for the share and provide the bank with a quantity bid $Q$, which is good throughout the region $\left[p-d_{p}, p\right]$;

$t_{4}$ The bank allocates shares to bidders. If there is excess demand for the issue then the bank exercises discretion in determining allocations.

Note that the bank's quoted discount $d_{p}$ is dependent upon $p$.

This staging of events corresponds with the institutional setting described in the preceding section. At $t_{0}$ the bank approaches key investors whose input is sought before establishing the indicative price range. Periods $t_{1}$ to $t_{3}$ correspond to the traditional staging of a bookbuilding effort. We search for equilibria in which the uninformed investors follow symmetric strategies. In doing so, we assume that the bank is able to commit at time $t_{0}$ to the following strategy: 
1. To make no ex post adjustments to the range $\left[p-d_{p}, p\right]$ quoted at time $t_{1}$;

2. To provide allocational preference in oversubscribed issues to uninformed traders;

3. To allocate all of the shares in oversubscribed issues at the top of the time $t_{1}$ range $(p)$ and in other issues at the bottom of the range $\left(p-d_{p}\right)$;

4. To cancel the share issue if $p \notin\left\{P_{l}, P_{h}\right\}$.

The first assumption reflects the empirical fact we seek to rationalize. Coupled with the second assumption, it provides the mechanism for penalising informed traders who fail to gather or misstate information. It is difficult to provide systematic evidence to support the assumption that uninformed investors are treated favourably in the event of oversubscription. However, there is considerable anecdotal evidence to suggest this is a reasonable assumption. A significant proportion of the "uninformed" are likely to be individual ("retail") investors. There are many examples of retail investors being favoured in allocation. For example, in the 2002 IPO of UK bookmakers William Hill, the final book was ten times subscribed. Retail investors had submitted just under $2 \%$ of the $£ 6.2 \mathrm{bn}$ of bids, yet were allocated $14 \%$ of the final offering. Similarly, in many countries that use hybrid offerings - combining an institutional bookbuilding with a public offering - it is quite common for there to be clawback arrangements, whereby if (total) demand is unexpectedly strong the size of the public offering is increased at the expense of the institutional bookbuilding. In general, when feedback is weak, lead managers also encourage syndicate members to broaden the retail network by pitching the deal more widely among retail brokers. But these brokers would have little incentive to exert effort on behalf of the syndicate if they expected their clients to be excluded from hot issues.

The third assumption ensures that uninformed traders oversubscribe only when they receive a windfall, or when they learn that the informed investor has reported an incorrect price, while guaranteeing the informed investor a payment $d_{p}$ for truthful reporting in the absence of a windfall. We assume that the reason for oversubscription is not observable by the investment bank. Of course, observed prices often are set within the bookbuilding range. In a more complex model one could accomplish this by endowing uninformed investors with noisy and uncorrelated signals of the issuer's type. In equilibrium, the quality of the uninformed investors' audit would be an increasing function of their aggregate demand, as would the issue price. This generalization would only obscure our essential point with additional complexity. 
The fourth assumption is designed to avoid off the equilibrium path outcomes: it will never be invoked. Although it is not time-consistent we assume that reputational considerations provide enforcement.

In equilibrium these commitments induce uninformed investors to bid for $\$ 1$ of the share if they learn (with probability $\lambda$ ) that $p<\tilde{P}$, or if (with probability $\beta$ ) they receive a windfall. If they learn that $p=\tilde{P}$ and investor 0 has bid for $\$ 1$ of the share then they will each bid for

$$
Q_{N R} \equiv \frac{S-1}{I}
$$

shares. This is the highest quantity which avoids rationing and so ensures an issue price of $\tilde{P}-d_{\tilde{P}}$ and hence yields a profit. Higher quantities result in rationing and hence by commitment (3) an issue price of $\tilde{P}$ and investor profit of $\$ 0$.

Now assume that investor 0 has used her information technology and so knows the realisation of $\tilde{P}$. The bank selects $d_{h}$ and $d_{l}$ to induce truthful reporting. ${ }^{16}$ It is obvious that the low state will always be reported truthfully ${ }^{17}$. Assume for the moment that uninformed traders will never bid for more than $Q_{N R}$ shares in the absence of a time $t_{2}$ signal: we demonstrate below that this assumption is correct in equilibrium. The truth-telling constraint in the high state is then $d_{h}(1-\beta) \geq\left(d_{l}+\Delta P\right)(1-\lambda)(1-\beta)$, or

$$
d_{h} \geq\left(d_{l}+\Delta P\right)(1-\lambda),
$$

where the multiplier $(1-\lambda)$ indicates that under reporting is discovered with probability $\lambda$. In this case the informed investor makes no profit from the IPO (since $I>S$ and uninformed investors receive allocation priority). Constraint $T T$ shows that the informed investor requires an incentive to reveal private information. ${ }^{18}$

The informed investor must also be induced to undertake costly information production, rather than making an uninformed report. If the truth-telling constraint $T T$ is satisfied, this requirement yields an incentive-compatibility constraint for each of the uninformed reports available to the informed investor:

\footnotetext{
${ }^{16}$ With a harmless abuse of notation, we write $d_{h}$ for $d_{P_{h}}$ and $d_{l}$ for $d_{P_{l}}$.

${ }^{17}$ Sherman and Titman (2002) consider a model in which the informed trader's information technology is imperfect. In this case the issue may be more accurately priced if more than one informed trader is asked to participate. With severe high state underpricing, the low state may not be reported truthfully if overstatement of quality yields preferential allocations. This places an upper bound upon IPO underpricing which does not arise in our model.

${ }^{18}$ Unlike previous work (see Benveniste and Spindt, 1989, Benveniste and Wilhelm, 1990 and Sherman and Titman, 2001), it need not follow that hot issues (those for which the fair price is revealed to be in the high state) are more heavily discounted than cold issues. We examine below the equilibrium conditions for this to be the case.
} 


$$
\begin{aligned}
\left(\pi_{h} d_{h}+\pi_{l} d_{l}\right)(1-\beta)-c & \geq\left(\pi_{h}\left(d_{l}+\Delta P\right)(1-\lambda)+\pi_{l} d_{l}\right)(1-\beta), \\
\text { or } d_{h} & \geq \frac{c}{(1-\beta) \pi_{h}}+\left(d_{l}+\Delta P\right)(1-\lambda) . \\
\text { and }\left(\pi_{h} d_{h}+\pi_{l} d_{l}\right)(1-\beta)-c & \geq\left(\pi_{h} d_{h}-\pi_{l}\left(\Delta P-d_{h}\right)\right)(1-\beta), \\
\text { or } d_{h} & \leq\left(d_{l}+\Delta P\right)-\frac{c}{(1-\beta) \pi_{l}} .
\end{aligned}
$$

The $(1-\beta)$ terms in these expressions reflect the fact that, when windfall investing occurs, informed traders will not make a profit, irrespective of whether or not they have gathered any price information. $I C_{l}$ assumes that uninformed investors will crowd out trader 0 if they discover that the issue is underpriced. Later, we derive conditions which ensure that this occurs. $I C_{l}$ implies $T T$, so the truth-telling constraint cannot bind. This occurs in our model because passively reporting the low state yields a combination of the returns from dishonest high state reporting and low state honesty. Information production can therefore only be incentivised if the high state discount is sufficient to compensate trader 0 for both her honesty and her information costs. ${ }^{19}$ Finally, observe that $I C_{l}$ implies that $\pi_{h} d_{h}+\pi_{l} d_{l}>c$ and hence that investor 0's participation constraint is automatically satisfied whenever the incentive-compatibility constraints are satisfied. Because the informed investor's participation constraint is slack, she earns a rent on her information technology.

The constraints $T T$ and $I C$ were derived assuming that uninformed investors bid only for $Q_{N R}$ shares in the absence of a time $t_{2}$ signal and thereby enable investor 0 to invest his entire wealth net of information costs in the offering. This will be the case provided

$$
d_{h}, d_{l} \geq 0
$$

When investor 0 is proved (with probability $\lambda$ ) by a time $t_{2}$ signal to have reported an untruthful low price, commitment (2) implies that uninformed investors can crowd him out by bidding $\$ 1$ each in the offering. They will elect to do so when

$$
\begin{aligned}
Q_{N R}\left(d_{l}+\Delta P\right) & \leq \frac{S}{I} \Delta P \\
\text { or } d_{l} & \leq \frac{\Delta P}{S-1}
\end{aligned}
$$

We have therefore proved the following:

\footnotetext{
${ }^{19}$ Sherman and Titman (2002) obtain a similar result in a model which has both endogenous information accquisition and strategic interaction between multiple informed traders.
} 
Proposition 1 When the investment bank commits to rules 1, 2,3 and 4 above and sets $d_{h}$ and $d_{l}$ to satisfy TT, IC, Pos and CO, it is an equilibrium for investor 0 to use his information technology and to quote the true price, and for uninformed investors to bid for $Q_{N R}$ shares.

Proposition 1 provides a rationale for the apparent unwillingness of banks to set offer prices above the indicative price range for European IPOs. A firm commitment to the indicative price range produces oversubscription when informed investors understate their information, and uninformed investors become informed exogenously. The bank responds to oversubscription by favoring uninformed investors with share allocations. The threat that uninformed investors will become informed exogenously, and crowd out informed investors, thereby disciplines informed investors, ensuring that they use their information technology and provide a truthful report of its output. Thus uninformed investors function similarly to the speculative monitors of Aghion, Bolton and Tirole (2004). Although the bank's optimal ex post response to overbidding would be to raise the price range, if uninformed investors anticipated this they would never oversubscribe a new issue. The disciplining role of uninformed investors would then be lost, and informed investors would not quote $\tilde{P}$ at time $t_{0}$. The bank's commitment never to adjust the price range is therefore central to our conclusions.

We now determine the investment bank's optimal policy. The bank's objective is to minimise the expected level of underpricing

$$
\pi_{l} d_{l}+\pi_{h} d_{h}
$$

subject to $T T, I C_{l}, I C_{h}$, and Pos. Recall that $T T$ is implied by $I C_{l}$. Figure 2 illustrates constraints $I C_{l}, I C_{h}$ and $C O$ in $\left(d_{l}, d_{h}\right)$ space, and also shows two iso-underprice lines: constraint Pos limits policies to the positive quadrant. The feasible contract region is shaded. The intersection between $I C_{l}$ and $I C_{h}$ occurs at

$$
d_{l}^{*} \equiv \frac{c\left(\pi_{l}+\pi_{h}\right)}{\lambda \pi_{l} \pi_{h}(1-\beta)}-\Delta P .
$$

Note that there are no feasible contracts if this expression exceeds $\frac{\Delta p}{S-1}$ : equivalently, if

$$
\lambda<\lambda^{N C} \equiv \frac{c}{\Delta P(1-\beta)} \frac{\pi_{l}+\pi_{h}}{\pi_{l} \pi_{h}} \frac{S-1}{S} .
$$

(NoContract)

When $\lambda \geq \lambda^{N C}$ it is clear from inspection of the iso-underprice lines in figure 2 that the optimal contract lies at the left-most point in the feasible contract region. This will be $\left(0, \frac{c}{\pi_{h}(1-\beta)}+\Delta P(1-\lambda)\right)$ 


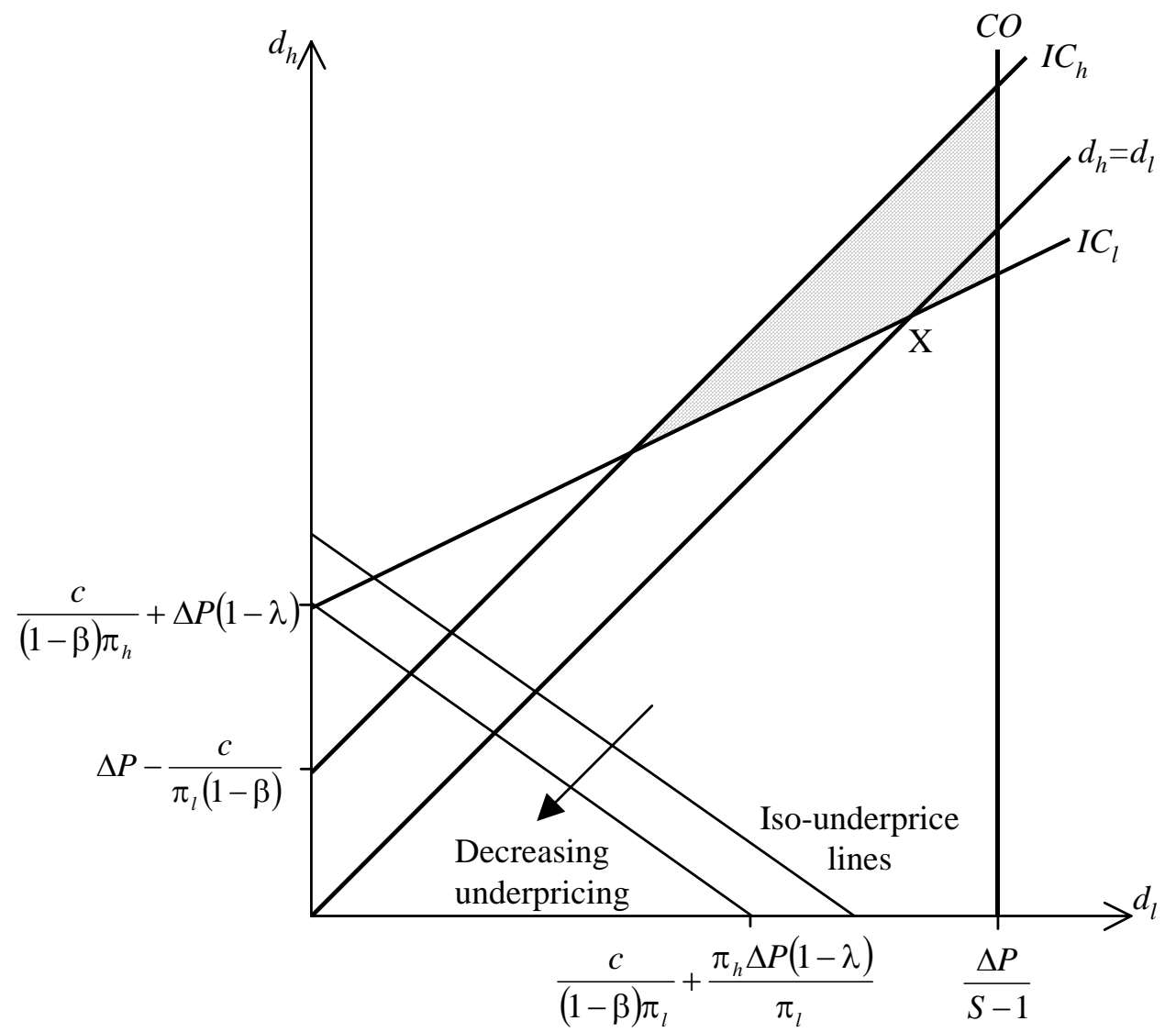

Figure 2: The feasible contract range.

if $d_{l}^{*} \leq 0$ : equivalently if

$$
\lambda \geq \lambda^{l 0} \equiv \frac{c}{\Delta P(1-\beta)} \frac{\pi_{l}+\pi_{h}}{\pi_{l} \pi_{h}} .
$$

(HotMktDiscount)

In this case, discounts occur only in hot markets where the fair price is revealed to be in the high state. Figure 2 illustrates the situation for interim $\lambda$ values $\left(\lambda^{N C} \leq \lambda<\lambda^{l 0}\right)$, when the optimal contract lies at the intersection of $I C_{l}$ and $I C_{h}:\left(d_{l}^{*}, d_{l}^{*}+\Delta P-\frac{c}{\pi_{l}}\right)=\left(\frac{c\left(\pi_{l}+\pi_{h}\right)}{\lambda \pi_{l} \pi_{h}(1-\beta)}-\Delta P, \frac{c\left(\pi_{l}+\pi_{h}(1-\lambda)\right)}{\lambda \pi_{l} \pi_{h}(1-\beta)}\right)$ and discounts can be positive in either hot or cold markets.

We summarise our discussion of optimal investment bank contracts in proposition 2 .

Proposition 2 Underpricing levels $\left(d_{l}, d_{h}\right)$ in the optimal bookbuilding contract with a single first stage investor and a fixed initial price range depend upon the probability $\lambda$ of exogenous learning in the following way:

1. If $\lambda<\lambda^{N C}$ then no contract achieves truthful reporting by informed investors; 
2. If $\lambda^{N C} \leq \lambda<\lambda^{l 0}$ then

$$
\left(d_{l}, d_{h}\right)=\left(\frac{c\left(\pi_{l}+\pi_{h}\right)}{\lambda \pi_{l} \pi_{h}(1-\beta)}-\Delta P, \frac{c\left(\pi_{l}+\pi_{h}(1-\lambda)\right)}{\lambda \pi_{l} \pi_{h}(1-\beta)}\right)
$$

3. If $\lambda \geq \lambda^{l 0}$ then

$$
\left(d_{l}, d_{h}\right)=\left(0, \frac{c}{\pi_{h}(1-\beta)}+\Delta P(1-\lambda)\right) .
$$

$\lambda^{N C}$ and $\lambda^{l 0}$ are defined in equations NoContract and HotMktDiscount respectively. Moreover, the expected level of underpricing is decreasing in $\lambda$.

Proof. Only the comparative static of the expected level of underpricing is not already proven. This follows trivially from the expressions in the statement of the proposition.

Exogenous learning by uninformed investors provides a means by which under-reporting can be penalised. Proposition 2 demonstrates that this is essential for our conclusions. When the probability $\lambda$ of learning is sufficiently low, under-reporting goes unpunished and it is impossible to incentivise information production (and hence revelation, since $I C_{l}$ implies $T T$ ). When an optimal bookbuilding contract exists, the expected level of underpricing is decreasing in $\lambda$ (in other words, in the severity of the penalty for misreporting), and the extent of underpricing is also decreasing, in that only hot issues are underpriced for sufficiently high $\lambda$.

Note that the size of the discount offered to the informed investor is increasing in the value of the parameter $\beta$. High levels of $\beta$ reflect large quantities of investable funds and hence we interpret high $\beta$ values as representing economic booms. The investment bank cannot distinguish between windfall investment and investment in response to learning and so must respond to both by crowding out the informed investor. In other words, crowding out at the top of the range is an equilibrium phenomenon in our model and will occur more in booming markets. In these markets there is a strong possibility that investors will not receive any compensation for gathering and disseminating information. To incentivise information production and reporting, informed traders must therefore receive higher price discounts on new issues which are not oversubscribed. ${ }^{20}$

To understand condition 1, oberve that uninformed investors with evidence of under-reporting have to choose between the enhanced allocation which they receive if they whistle-blow, and sharing in the returns on misinformation. A feasible contract exists only if they prefer the enhanced allocation (constraint $C O$ ). This observation is captured by the last term $\frac{S-1}{S}$ in equation NoContract.

\footnotetext{
${ }^{20}$ Note that since oversubscribed issues are not underpriced, average realised underpricing need not be increasing in $\beta$. To see this, note that the expected unconditional underpricing level is $(1-\beta)\left(\pi_{l} d_{l}+\pi_{h} d_{h}\right)$, which from proposition 2 is increasing when $\lambda^{N C} \leq \lambda<\lambda^{l 0}$, and decreasing when $\lambda \geq \lambda^{l 0}$.
} 
If this term is large, then the increased allocations from crowding out informed investors are insufficient to incentivise truthful reporting. In a simple extension of the model the investment banker could resolve the problem by inviting several informed traders to participate in the information acquisition stage (time $t_{0}$ ), thus reducing the allocations received by uninformed traders if they do not crowd out the informed investors.

Conditions 2 and 3 respectively describe the circumstances where all issues are underpriced, and where only hot (high state) issues are underpriced. To understand them, we must think about trader 0's information production incentives. If she passively reports the low state, then she will earn $d_{l}$ if her report turns out to be true and, provided she is not crowded out, will otherwise earn $\Delta P+d_{l}$. She can be incentivised to gather information instead by a sufficiently large discount $d_{h}$ on hot issues. As $\lambda$ decreases, passive reporting of the low state is more likely to be profitable, and so the hot issue discount $d_{h}$ required to incentivise information gathering increases.

Now consider trader 0's incentives passively to report the high state. In this case, she will earn the hot issue discount $d_{h}$ whenever her report turns out to be correct, and will otherwise lose $\Delta P-c$. She will never be crowded out and so decreases in $\lambda$ only matter to her because they result, through the effect already identified, in a higher $d_{h}$. This has two consequences: it increases her profits from correct reports; and it reduces her losses from incorrect reports. She can be incentivised to gather information rather than to make this passive report by an increase in $d_{l}$.

For sufficiently low $\lambda\left(\lambda<\lambda^{l 0}\right), d_{h}$ will be so high that passive high state reporting can only be avoided by providing a strictly positive low state discount. This corresponds to condition 2 of proposition 2. For higher $\lambda\left(\lambda \geq \lambda^{l 0}\right)$, a lower hot issue discount $d_{h}$ serves to incentivise information production over passive low state reporting, and no cold issue discount is required to discourage passive high state reporting. This corresponds to condition 3 of the proposition.

Our conclusion that even "cold" issues should be discounted when $\lambda<\lambda^{l 0}$ contrasts with the traditional argument that discounts compensate informed agents most efficiently when they are extended in positive feedback states (Benveniste and Spindt, 1989, and Benveniste and Wilhelm, 1990). This difference is a consequence of the asymmetric crowding out effects in high and low states of the world and the need to incentivise information production. In a slightly different context, Sherman and Titman (2002) obtain a similar result. In fact, we can go further. Since $d_{h}$ incentivises information production, it must be increasing in the cost $c$ of information. For sufficiently high $c, d_{h}$ may be so high that passively reporting a hot issue can only be discouraged by a cold issue 
discount $d_{l}$ which exceeds $d_{h}$. This occurs when $I C_{l}$ intersects $I C_{h}$ to the right of the intersection of $I C_{l}$ and $d_{l}=d_{h}$ (point $\mathrm{X}$ in figure 1). It is easy to show that this occurs precisely when

$$
c>\pi_{l} \Delta P(1-\beta) .
$$

To interpret this expression, observe that the incentives passively to report a hot issue are greatest when the probability of a cold issue is low, when there is little variance in the true price, and in a boom market when the likelihood of receiving any payment for information gathering is low. All three of these factors are reflected in equation 1.

\section{Discussion and Extensions}

We argue that institutional differences between the European and US systems of bookbuilding explain the relative immutability of European bookbuilding ranges. Our basic intuition is that when, as in Europe, information is gathered before the announcement of a bookbuilding range, information gathering and revelation will be induced by the threat that exogenously informed outsiders will oversubscribe the issue. Although the simple model of section 3 captures our main idea, it does not explore some important questions in bookbuilding design. In this section we discuss the importance in our model of two-stage information acquisition. We then explore the impact upon our argument of relaxing our assumptions that there is only one informed agent with a perfect signal, and that the number of uninformed investors is uncertain.

In summary, we argue below that our results are robust to the introduction of multiple informed traders and of imperfect signals. In both cases, the uninformed traders continue to have a role as $e x$ post auditors. This will affect the bookrunner's first stage optimisation problem. Hence, our results could be viewed as complementary to Sherman's (2003). Sherman argues that bookbuilding is superior to more standard auction-based approaches to floatations because it allows the bookrunner to control access to the IPO and hence to provide the right incentives for information-gathering and revelation. Our work extends hers: when information exchange can occur before the offering, we describe a role for a two-stage information gathering process with a book-building range which allows uninformed traders to participate in the IPO. The bookrunner continues to act as a gate-keeper, but is now concerned primarily with restricting the number of informed traders who participate in the pre-marketing stage. With pre-marketing information exchange, there is far less need to restrict access to the book. 


\subsection{Two-Stage Procedure}

Our model rests upon the possibility that uninformed agents will acquire price information and oversubscribe the issue in the event that informed agents under-report their information. This is accomplished via a two-stage procedure in which information gathered from informed agents in the first stage is publicised via a quoted price range, before uninformed agents have an opportunity to bid in the second period. This two-stage approach reflects procedures used in real world bookbuildings: we argue below that it is an optimal way to gather information and to audit the results. In addition, the two-stage process casts some light upon the mechanisms by which underwriters commit themselves to a specific pricing and allocation mechanism.

Could the underwriter use the uninformed traders as auditors with a single-stage sealed bid offering? If all investors submitted simultaneous (price, quantity) bids, then oversubscription at the prices quoted by informed traders could be taken, as in our model, as evidence of underreporting, and punished through low allocations. We argue that, for a number of reasons, it would be harder to run a sealed bid auction of this type.

Firstly, we argue below that the bookrunner will probably want to limit informed trader access to the IPO: as Sherman (2003) argues, this may be hard to achieve in a single-stage auction. Secondly, oversubscription at the specific price quoted by informed traders would probably be observable only if uninformed traders entered a demand curve. This may be hard to coordinate. Thirdly, if uninformed traders have special information then including them in the first round of the bookbuilding would create opportunities for them to behave strategically: they might for example under-report their information. Requiring the bookrunner to design a mechanism to discourage this type of behaviour adds additional complexity. Moreover, insofar as uninformed traders are constrained in their order size (this could apply equally to an index fund or to a personal investor), the bookrunner's ability to reward truth-telling through high allocations may be circumscribed. Finally, although we do not model this effect, it is possible that uninformed trader signals are imprecise and that they are not able to give specific price bids. They may find it easier to evaluate the issue if they have a price range to work from. In contrast to a sealed bid auction, a price range which reflects first stage information production presents uninformed traders with a simple choice: accept the informed traders' price estimate, or reject it as being too low. This simple choice is not subject to strategic responses of the type mentioned above. 
While other theoretical work on bookbuilding acknowledges the importance of underwriter commitment, typically it simply assumes that it can be achieved. We argue that one means of generating commitment may be a two-stage allocation procedure with interim communication, as in our model. The price range is an unambiguous communication by the bookrunner. Insofar as the bookrunner's reputation is undermined by deviations from the quoted range, the range may therefore be a valuable commitment device: deviation from the pricing and allocation mechanisms of our model will be immediately observable, and so will be punished in later book-building exercises.

A final justification for the two-stage marketing procedure of our paper relates to work by Chowdry and Sherman (1996). Cowdhry and Sherman point to the phenomenon of "information leakage," when uninformed traders learn proprietary information about new issues priced some days before they are closed to new bids. For example, information leakage may occur through newspaper articles, or through learning about loan applications to fund stock purchases. Chowdhry and Sherman argue that information leakage may present a cost to the issuer. We argue that to the contrary that, if information leakage occurs, it may provide positive incentives for revelation by informed traders, who will be punished for under-reporting if their true valuations permeate the broader market. If delaying the consumation of the issue increases the likelihood of information leakage, then such delays may be desirable. Hence, although in our model the basis for signals to uninformed traders is exogenous, if such signals were in large part attributable to information leakage then the need to generate some leakage would provide an additional reason for a two-stage book-building process.

\subsection{Competition Between Informed Agents}

Our assumption that only one agent is potentially informed is clearly a simplification. With more than one trader, the bookrunner can condition allocations upon all of the information she receives. This has two consequences: firstly, the informed traders can be incentivised to whistle-blow on one another; and secondly, when the informed traders receive imperfect signals, more accurate pricing will be achieved by amalgamating their signals.

Some earlier work has examined these effects. Benveniste and Wilhelm (1990) allow for technologies which yield uninformative signals. Sherman and Titman (2002) combine these technologies with costly information production, and determine the optimal number of traders to incentivise 
information-gathering and revelation. In our model, information production occurs at the premarketing stage and the book-builder's corresponding problem is therefore to determine the number of informed agents who participate at this stage. A related question concerns the impact in our set-up of allowing the information technology to return an uninformative signal, and hence facilitating free-riding between the informed traders.

One immediate observation is that, although we do not model this in section 3 , the informed trader may be unnecessary when $\lambda$ is close to 1 : in this case, the bookrunner's problem is inducing information revelation, rather than production, as in Benveniste and Spindt (1989). ${ }^{21}$

Suppose that $\lambda$ is sufficiently low for some informed trader effort to be desirable. In this case, Sherman and Titman (2002) show that increasing the number of traders will facilitate information revelation: collusion on under-reported prices can be prevented by rewarding whistle-blowers with enhanced allocations. The cost of an increased number of traders is a reduced equilibrium share allocation to each trader, which increases the level of underpricing necessary to incentivise information production.

In our simple model, signals are perfect and so increasing the number of traders would not affect the quality of the bookrunner's signal. Enhanced revelation incentives could be achieved by increasing the number of traders to two: in this case, the uninformed second stage investors would have no role to play. In our model investments are bounded above at $\$ 1$, which diminishes the bookrunner's ability to manage allocations. However, we know from Sherman and Titman's work that in a more general model, the trade-off between the two auditing mechanisms would hinge upon the relative sizes of second stage information revelation (measured by $\lambda$ ), and the deliterious incentive effects of reduced equilibrium allocations. For sufficiently large $\lambda$, auditing by outside investors would dominate. Although we do not model this, the argument of the previous section suggests that $\lambda$ could be managed to an appropriate level by controlling the extent of information leakage.

Now consider an extension of our model to allow for uninformative signals. Increasing the number of traders would then make for a more accurate aggregate signal. Moreover, as modelled by Sherman and Titman (2002), informed traders could free-ride upon one another's information production efforts by exerting no effort and declaring an uninformative signal. In this case, the

\footnotetext{
${ }^{21}$ Recall, though, from the previous section, that $\lambda$ may be a function of information leakage, in which case it is never optimal to reduce the number of informed traders to zero.
} 
bookrunner would have the option of penalising multiple informed traders with a zero allocation in the event of second stage oversubscription by uninformed traders. Hence, uninformed traders would have a role in sharpening disclosure incentives even in the presence of multiple informed traders. This would potentially reduce the number of informed traders needed in the first round, and hence reduce equilibrium underpricing.

Finally, we revisit the cold issue discounts which arise in our model for low $\lambda$ values. Recall that cold issue underpricing is necessary to discourage passive high state reporting in the presence of a large hot issue discount. Competition amongst informed traders will not stamp out passive high state reporting, since whistle-blowing is incentivised by rewarding the highest bidder. The existence of a cold issue discount will therefore hinge upon the size of the hot issue discount with multiple stage one investors. The hot issue discount incentivises information production over passive low state reporting. With many informed traders, a sole information producer earns extra high state returns through preferential allocation. The extent of the hot issue discount will therefore depend upon the difference between the allocation which all traders receive when passively reporting the low state, and the allocation which one receives when whistle-blowing in the high state. In our model of cash constrained informed traders, the allocation is $\$ 1$ in both cases and the cold issue discount persists. In a model with unconstrained traders, the size of the cold issue discount will decrease in the number of informed traders, until it eventually reaches zero. ${ }^{22}$

\subsection{Uninformed Trader Numbers}

One of the stronger assumptions in our formal model is that the number $I$ of uninformed traders is common knowledge and hence that in the absence of a signal, they are able to coordinate upon a bid of $Q_{N R}$. In practice, the number of uninformed traders in the market seems likely to be a random variable whose realisation is not widely known. In this case, oversubscription could occur by chance. This would clearly weaken the mechanism which we describe.

This problem could be easily resolved if the bookrunner were to control access to the second stage of the book-building, as well as the first. Sherman (2000) examines a dynamic model of bookbuilding in which such restricted access is optimal, because it allows the bookrunner to reduce

\footnotetext{
${ }^{22}$ Cold issue discounts are also a feature of Bias, Bossaerts and Rochet (2002), who model an IPO in which the investment banker colludes with the informed investors against the issuer and the uninformed investors. However, in their model discounts simply reflect the cost of inducing information revelation, whereas in our model the informationgathering incentives always bind so that discounts reflect the cost of incentivising information production.
} 
the rent accruing to uninformed traders. In our model, selecting a number of traders to act as the uninformed agents, and publicising their number, would allow coordination of the type which we discuss, and would also ensure that share allocations were large enough to be feasible. This approach would be in line with Sherman's (2003) work, which argues that the superiority of bookbuilding derives from the ability of the bookrunner to control access to the IPO so as to generate the most effective environment for information gathering and revelation.

\section{Conclusion}

Although there are many similarities in the way bookbuilding occurs in different countries, changes in the "micro-structure" of the IPO process can have important implications. In this paper we have focused on one such detail: how differences in the interpretation of securities laws in Europe (as compared with the US) allow the exchange of information between investors and the issuing bank prior to the bookbuilding period. As a result, the staging of the information revelation game changes significantly. In contrast to the existing literature, where all information is revealed during the bookbuilding period, in our model information acquisition takes place prior to establishing the initial indicative price range. As a result, while recent work has concentrated on the value of restricting entry to the book, in our model the bookbuilder's primary role is as gate-keeper for the pre-marketing stage. A commitment to pricing within the indicative range promotes both costly information production and its revelation. This result assumes that it is possible for private information to be revealed exogenously to uninformed investors before the final offer price is set and that uninformed investors receive allocation priority in the event of oversubscription. Under these assumptions, the threat to informed investors of being crowded out of the offering if they fail to reveal positive information ensures information production and revelation.

This model suggests that for those countries where the exchange of information can occur before the bookbuilding period, the initial price ranges will be "sticky" and relatively unresponsive to demand as revealed during the bookbuilding stage. This is indeed what is observed. For instance, in Europe in only one tenth of IPOs is the final price set outside the initial price range. In contrast, nearly one-half of all US IPOs are priced outside the initial range. Although it is tempting to infer that the unresponsiveness of prices to revealed demand in Europe is inefficient, our model suggests otherwise. Furthermore, although we do not conduct a full analysis of the determinants 
of IPO pricing, the stylised facts we present are also consistent with our model. If significant information acquisition occurs prior to establishing the indicative price range for European IPOs, their indicative price ranges should be systematically more informative than indicative price ranges for comparable US IPOs. For most European countries, average underpricing for bookbuilt IPOs is no higher than that observed in the US notwithstanding the infrequent revisions to price ranges. However, there is some variation across countries (which, we suspect, may reflect other differences in their IPO micro-structure) and we leave for future research a systematic empirical analysis.

The model yields several testable hypotheses and implications for empirical analyses of European primary market data. First, the mechanism is more powerful if exogenous revelation of private information is more likely. It seems plausible that this likelihood is a function of both firm (technological) characteristics and, more generally, the micro-structure of the IPO process in a given country. Similarly, it is plausible that the threat to informed investors of being crowded out varies across markets and time. Empirical applications or tests of the theory clearly warrant case-specific analysis of the plausibility of these assumptions.

Second, our model suggests that investors should earn rents for information revealed before the bookbuilding period. In a recent paper Aussenegg et al. (2002) conclude that the evidence from the German Neuer Markt is consistent with this prediction, and that the main role of the bookbuilding phase is to determine the allocation of the shares, rather than to gather pricingrelevant information. Furthermore, Jenkinson and Jones (2004), in their analysis of 27 European IPOs, find that only $7 \%$ of bids submitted during the bookbuilding are price sensitive, and that there is no evidence that such bids are favoured in allocation. Again, this evidence is consistent with the predictions of our model. ${ }^{23}$

Third, the need to avoid significant communication with US investors prior to registration suggests that information acquisition will differ markedly between domestic and global offerings. Ljungqvist, Jenkinson and Wilhelm (2003) suggest that more information per unit of reward might be extracted from US investors. Thus even after seeking pre-marketing feedback for a global offering from potential investors outside the US, feedback from US investors during the bookbuilding effort might remain informative at the margin. If so, price sensitive bids from (US) investors might plausibly be rewarded with larger allocation and also prove more influential than others in

\footnotetext{
${ }^{23}$ The evidence on how investors bid in European bookbuildings is, however, varied. Using a sample of IPOs and secondary offerings Cornelli and Goldreich (2001, 2002) document that $20 \%$ of bids were price sensitive, and that such bids were favoured in allocation.
} 
determining the offer price. By contrast, the pre-marketing effort might serve as the dominant mechanism for acquiring information in domestic offerings. Consequently, we might expect both a stronger commitment to the indicative price range, and a weaker linkage between allocations and the price sensitivity of bids in the book, than would be observed for comparable global offerings.

Finally, it is clear that our model relies on the assumption that significant exchanges of information occur between certain investors and members of the IPO syndicate before the bookbuilding. Whilst we have provided general evidence to support this assumption for European IPOs, there remains little direct and detailed evidence regarding the sort of information that is actually elicited. This pre-marketing phase of the bookbuilding process in Europe is an important area for future empirical research.

\section{References}

Aghion, P., Bolton, P., Tirole, J., 2004. Exit options in corporate finance: Liquidity versus incentives. Review of Finance 8, $327-353$.

Aussenegg, W., Pichler, P., Stomper, A., 2002. Sticky prices: IPO pricing on Nasdaq and the Neuer Markt. Working paper, Vienna University and Boston College.

Benveniste, L. M., Spindt, P. A., 1989. How investment bankers determine the offer price and allocation of new issues. Journal of Financial Economics 24, $343-361$.

Benveniste, L. M., Wilhelm, Jr., W. J., 1990. A comparative analysis of IPO proceeds under alternative regulatory regimes. Journal of Financial Economics 28, $173-207$.

Bias, B., Bossaerts, P., Rochet, J.-C., 2002. An optimal IPO mechanism. Review of Economic Studies 69, $117-146$.

Bradley, D. J., Jordan, B. D., Ritter, J. R., 2003. The quiet period goes out with a bang. Journal of Finance 58, $1-36$.

Busaba, W. Y., Chang, C., 2002. Bookbuilding vs. fixed price revisited: The effect of aftermarket trading. Working paper, Unversity of Western Ontario, ON, Canada.

Chemmanur, T. J., 1993. The pricing of initial public offerings: A dynamic model with information production. Journal of Finance 48, 285 - 304. 
Chowdry, B., Sherman, A. E., 1996. International differences in oversubscription and underpricing of IPOs. Journal of Corporate Finance 2, $359-381$.

Cornelli, F., Goldreich, D., 2001. Bookbuilding and strategic allocation. Journal of Finance 56, 2337 $-69$.

Cornelli, F., Goldreich, D., 2003. Bookbuilding: How informative is the order book? Journal of Finance 58, 1415 - 1444 .

Hanley, K. W., 1993. The underpricing of initial public offerings and the partial adjustment phenomenon. Journal of Financial Economics 34, 231-50.

Jenkinson, T., Jones, H., 2004. Bids and allocations in European IPO bookbuilding. Journal of Finance 59, $2309-2338$.

Ljungqvist, A. P., Jenkinson, T., Wilhelm, Jr., W. J., 2003. Global integration in primary equity markets: The role of U.S. banks and U.S. investors. Review of Financial Studies 16, 63 - 99.

Löffler, G., Panther, P. F., Theissen, E., 2002. Who knows what when? - the information content of pre-IPO market prices. Working paper, Goethe-University, Frankfurt.

Ritter, J. R., 2003. Differences between European and American IPO markets. European Financial Management 9, $421-434$.

Sherman, A. E., 1992. The pricing of best efforts new issues. Journal of Finance 47, $781-790$.

Sherman, A. E., 2000. IPOs and long-term relationships: An advantage of book building. Review of Financial Studies 13, $697-714$.

Sherman, A. E., 2003. Global trends in IPO markets: Book building vs. auctions with endogenous entry. Mimeo, Mendoza School of Business, University of Notre Dame.

Sherman, A. E., Titman, S., 2002. Building the IPO order book: Underpricing and participation limits with costly information. Journal of Financial Economics 65, 3- 29.

Tinic, S. M., 1988. Anatomy of initial public offerings of common stock. Journal of Finance 43, 789822 . 


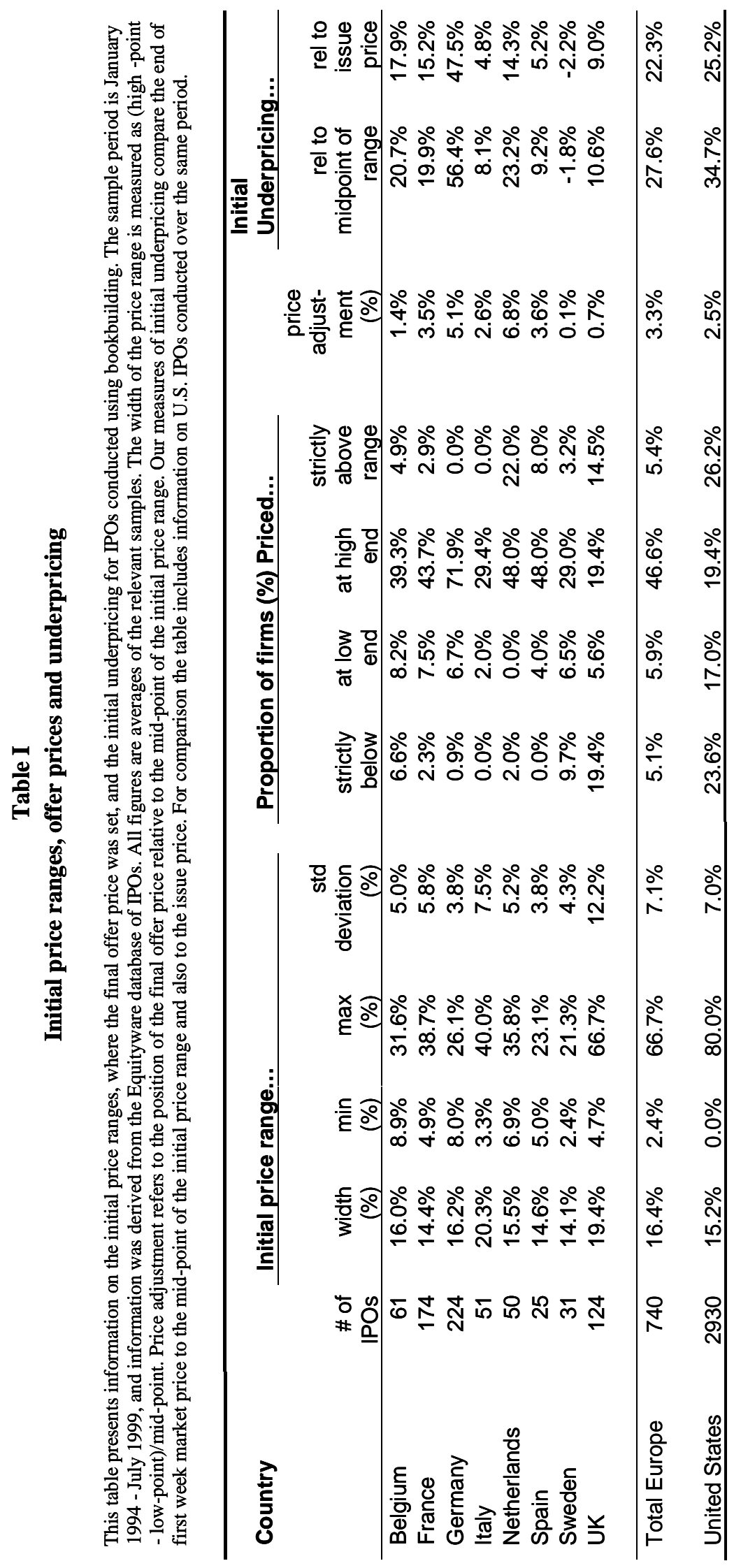

